\title{
O MITO DA DEMOCRACIA RACIAL NA EDUCAÇÃO INFANTIL E NOS ANOS INICIAIS DO ENSINO FUNDAMENTAL
}

\author{
Thaiza da Silva Garcia ${ }^{1}$ \\ Ielva Maria Costa de Lima Ribeiro²
}

\begin{abstract}
RESUMO
O presente artigo tem como objeto de estudo o mito da democracia racial na Educação Infantil e nos anos iniciais do Ensino Fundamental, tendo como ponto de partida a obra de Gilberto Freyre Casa Grande e Senzala, de onde se origina a ideia de democracia racial e a análise do currículo escolar diante dessa negativa social, bem como a normativa que torna obrigatório o ensino da cultura e o legado dos povos afrodescendentes; a lei 11.645/08 tem sido abordada nas práxis escolares e até na construção delas por meio do currículo real, oficial e oculto.
\end{abstract}

PALAVRAS-CHAVE: racismo. educação. formação docente.

\begin{abstract}
The following article focuses on the myth of racial democracy in early childhood education and in the early years of elementary school, taking as its starting point the work of Gilberto Freyre Casa Grande e Senzala, from where the idea of racial democracy and the school curriculum in the face of this social negativity originate, as well as the norm that makes the teaching of culture and the legacy of Afro-descendant peoples. Law 11.645 / 08 has been addressed in school praxis and even in its construction through the real, official and hidden curriculum.
\end{abstract}

KEY WORDS: racism. education. teacher training.

\section{INTRODUÇÃOO}

Este artigo é decorrente do trabalho de conclusão de curso de graduação em pedagogia, ministrado pelo Instituto Superior Anísio Teixeira- ISAT nos anos de 2018 a2019, e objetivou investigar os impactos do mito da democracia racial na Educação Infantil e nos anos iniciais do Ensino Fundamental através do currículo escolar, verificando ainda se esse currículo cumpre o que está disposto na lei 11.645/08, na qual torna obrigatório o ensino da história e da cultura africana.

${ }^{1}$ Graduada em Pedagogia pelo Instituto Anísio Teixeira - ISAT

${ }^{2}$ Mestra em Psicologia pela Universidade Salgado de Oliveira - UNIVERSO 
Ao esmiuçar as efemérides, os materiais didáticos,as práxis e a cotidianidade da escola em relação aos temas ligados ao legado africano nascem este trabalho, que visa evidenciar instrumentos escolares capazes de enfrentamento do racismo e do mito da racial.

\section{O QUE É DEMOCRACIA RACIAL}

O termo democracia racial foi fundamentado após o estudo feito pelo antropólogo Gilberto Freyre, na obra Casa Grande e Senzala, aonde chega ao entendimento que a sociedade portuguesa na colonização tinha como característica a aceitação de outros povos e culturas a fim de garantir expansão territorial. Por isso, era comum haver traços consanguíneos entre o colonizador e o colonizado, sendo isto um fator diferenciador entre os lusitanos e o resto dos habitantes do continente europeu.

Logo, a ideia de uma corrente ideológica como a da democracia racial contradiz a realidade enfrentada no Brasil e em qualquer outra nação que tenha nascido pela colonização. Segundo tal autor, o que ilustraria a possibilidade de relações pacíficas e harmoniosas no tempo presente, foi o encontro das culturas africanas e hegemônicas que se multiplicaram estreitamente, e que não havia distinção social, pois tolerava benignamente a chamada colonização híbrida (FREYRE 1930, p.65-73).

Tal corrente foi moldando as justificativas da sociedade para a ocultação do racismo e do preconceito. Essa tentativa veio acompanhada de um conjunto de desigualdades, certamente por esta razão a superação das problemáticas oriundas das questões étnicas raciais fica comprometida, mesmo havendo uma crescente conscientização sobre o tema, (REIS, 2009 p.445).

Entretanto, há motivos para que se perpetue esse pensamento, por meio do esforço para se manter a negativa social através da ideologia apresentada. Neste sentido se faz pertinente a reflexão que é feita por Santos na obra "O que é o racismo?":

Por que boa parte dos brasileiros ainda acredita que vivamos numa "democracia racial'? Para começar, porque as elites que nos governaram até hoje precisavam vender esta mentira, aqui e no exterior. A cabeça de uma sociedade é, em geral, feita pela sua classe dominante - com o objetivo duplo de manter seus privilégios e deixá-la dormir em paz. (SANTOS 1984, p.43).

É possível observar o efeito camuflagem desta ideologia, pois encobre as faltas e normatiza questões oriundas das muitas questões étnico-raciais que são; sociocultural, 
socioeconômico e meritocrático. Por isso essa tentativa histórica de imposição deste pensamento em nível de inconsciente coletivo.

Tais questões sociais deságuam na escola, onde todas as diferenças e problemáticas se encontram. Será que o corpo docente da escola está atento ou simplesmente normatiza ou singularizam questões plurais oriundas das muitas culturas que construíram a identidade brasileira? Será que o currículo abre espaço para discussões sobre temáticas a serem superadas, como a democracia racial?

Apesar de muitas conquistas ainda se precisa voltar o olhar para a cotidianidade tanto da sociedade e da escola como um todo, para investigar; o quanto se progrediu e o quanto se precisa avançar, no sentido de reconhecer que não há igualdades e que se devem reconhecer as desigualdades em todos os seus âmbitos e camadas sociais.

\section{DA DEMOCRACIA RACIAL AO RACISMO, E ÀS CONTRADIÇÕES SOCIAIS}

As questões relacionadas aos negros no Brasil demonstram a necessidade de reconhecer e discutir sobre os desdobramentos impostos pela negativa das diferenças no trato das problemáticas enfrentadas, ou simplesmente vividas por afrodescendentes. É notório que a segregação, ocorre de forma a se naturalizar como a própria ideologia da democracia racial. Logo, o discurso mais difundido e defendido pelos defensores do mito da democracia racial em questão, usa o princípio pétreo da Constituição Federal de 1988 em seu artigo $5^{\circ}$ e $6^{\circ}$, que dispõem sobre o direito a isonomia e a garantia de direitos sociais, ficando definindo que:

\footnotetext{
Art. $5^{\circ}$ Todos são iguais perante a lei, sem distinção de qualquer natureza, garantindo-se aos brasileiros e aos estrangeiros residentes no País a inviolabilidade do direito à vida, à liberdade, à igualdade, à segurança e à propriedade ...

Art. $6^{\circ}$ São direitos sociais a educação, a saúde, a alimentação, o trabalho, a moradia, o transporte, o lazer, a segurança, a previdência social, a proteção à maternidade e à infância, a assistência aos desamparados, na forma desta Constituição. (BRASIL,1988).
}

Entretanto, a pesquisa intitulada Retrato das Desigualdades de Gênero e Raça realizadas pelo Instituto de Pesquisa Econômica Aplicada (IPEA)em conjunto com a Pesquisa Nacional por Amostra de Domicílio (PNAD) de domínio do Instituto Brasileiro de Geografia e Estatística (IBGE), o IBGE demonstram que os princípios da isonomia e da 
ideologia apresentada neste estudo divergem, pois mostram as diferenças em percentuais que confirmam as desigualdades raciais. Pesquisa de âmbito nacional que apresentou dados coletados de 1995 a 2015 se traduz em seguintes dados: Os salários e remunerações divergem acentuadamente, pois o homem branco ganham em média $\mathrm{R} \$ 2.509,7$ e a mulher branca valor acima de $\mathrm{R} \$ 1.500,00$ mês, já o homem negros $\mathrm{R} \$ 1.500,00$ e a mulher negra por base de R $\$ 1.027$, 5.Quando o assunto é educação, entre mulheres brancas com 15 ou mais anos de idade são observados os valores percentuais de 4,9\% de analfabetismo, enquanto entre as mulheres negras o valor praticamente dobra, pois são observados taxa de 10,2\%. Percentuais não divergem entre os homens. Já no campo acadêmico, a permanência ou tempo médio de estudo é $25,9 \%$ anos para pessoas brancas, enquanto $12 \%$ anos para pessoas negras.

Tais números derrubam a ideia de "igualdade racial", pois evidencia que a cor da pele influência nas posições dentro e fora das camadas e níveis sociais e que é fator determinante e segregador como apontam as pesquisas. $\mathrm{O}$ conceito de isonomia não atende todas as demandas advindas dessas desigualdades, senão há diferenças sociais, como esses dados se explicam, mesmo havendo políticas que tentam a reversão de tal abismo social? Segundo GUIMARÃES (2001) o panorama de mudança seria demorado, pois os conjuntos de características que foram introduzidos por meio do senso comum para que houvesse o rebaixamento dos afrodescendentes, tais como a sua suposta incapacidade intelectual e cultural, enfraquecem as tentativas de reivindicações para mudança do status dentro da sociedade; dificultando assim as tentativas de discussão sobre a democracia racial e o racismo, sua existência e sua afirmação e ação sobre os multisetores da sociedade brasileira.

Sendo possível crer, que a cerne da questão indenitária dos afrodescendentes estaria na falta de representatividade social e cultural, pois há um entrave histórico que compromete a forma de como o negro compreende a si mesmo, e se reconhece diante de situações-problemas e até no reconhecimento do racismo, já que em sua formação o repertório histórico-social e seus conjuntos de singularidades que privilegiam uma cultura na qual ele está, mas não se vê e nem faz parte.

A situação apresentada pode encontrar nas representações sociais explicação para a sua manutenção na sociedade. Como evidenciam Caloti e Amorim (2015), "as representações sociais são percepções, ideias, opiniões, imagens, valores, crenças, atitudes, princípios; com os quais significamos a realidade, fenômenos sociais e circunstâncias que 
originam as condições de existência individual e coletiva." (CALOTI e AMORIM,2015, p.46).Em suma, segundo os autores, tais representações são formas de conhecimento socialmente elaboradas e partilhadas, possuindo orientação prática e concorrendo para a construção de uma realidade comum a um determinado conjunto social.

Entretanto, o discurso de igualdade propõe a democracia racial anulam as tentativas de diálogo sobre as interações sociais, remontando e retornando ao pensamento de FREYRE sobre a construção híbrida e plural que privilegia a cultura do colonizador, e agrega nuances culturais de outros povos hegemônicos, no entanto despreza as oriundas de continente africano.

Neste contexto, o não se reconhecer negro, a necessidades de grupos sociais se apropriarem culturalmente da cultura dos colonizadores é uma forma de se enquadrar e se parecer com os donos da "Terra." Reconhecer-se negro nesse contexto é uma construção social deteriorada e inferiorizada em outras esferas que são elas: política, religiosa, cultural e social.

\section{A SEGREGAÇÃO RACIAL NA QUESTÃo DO CAPITAL}

Para se entender como surgem os segregados raciais e os indicadores atuais expostos neste estudo se faz necessário rever questões históricas que culminaram na feitura do ideário racista e na construção de sua negação, pela visão do capital. A expansão marítima e ganhos territoriais estão no topo do ranking dos motivos pelas invasões e por consequência as colonizações e de se escravizar seus habitantes, sendo a maior parte dos escravizados do continente africano. Esta situação também permitiu reafirmar territórios pelo mundo no século XV e que se perpetuaria nos séculos posteriores.

Motivos para se justificar a dominação territorial e a escravidão, estavam ligadas a crenças religiosas e a superioridade contida na cor da pele. $\mathrm{Na}$ verdade o que determinou todo esse caminho de desigualdades e exploração foram o acúmulo de riquezas como; minerais, metais, pedras preciosas, especiarias e o material humano por parte dos que tinham e desejavam manter-se no poder e dominação. (SILVA e BERTOLDO, 2010.p.109).

Analisar o racismo sob ponto de vista do capital, possibilita perceber um dos motivos que se levaram as grandes expedições e todo o percurso que se deu a colonização 
até a escravidão sobre povos segregados, mas que eram importantíssimos na captação ou crescimento de capital econômico dos grupos dominantes. Segundo Viana (2009):

\begin{abstract}
A acumulação primitiva de capital produziu o modo de produção escravista colonial e o tráfico negreiro. A polêmica sobre os motivos da adoção dos trabalho escravo dos negros africanos continua viva, mas podemos concordar com a tese de que o tipo de produção implantada nos países escravistas exigia uma grande quantidade de força de trabalho não encontrada nem no local de produção nem na Europa ocidental e daí a necessidade de buscá-la na África. (VIANA, 2009, p.25).
\end{abstract}

Logo se faziam necessários modos ideológicos operantes para reafirmar a necessidade do explorar povos onde as relações de poder dominavam tais grupos sociais. A colonização brasileira foi protagonizada por colonos europeus, que utilizaram o racismo como argumento para que ocorresse de forma legalizada nos contextos jurídicos, religiosos e científicos, fato este que contrapõe-se a ideia de democracia racial.

É preciso perceber que fomentar realmente a ideia de um "mito de democracia racial" foi muito importante, pois acreditar nesta verdade, fazer com que fosse aceita, seria um facilitador para o aumento de capital tanto econômico quanto hierárquico nas questões ligadas as relações de poder.

Posteriormente, com a abolição da escravatura o status desse sujeito tirado de sua pátria, desconstruído de valores em todos os sentidos por uma sociedade que o calou e reinventou novos valores negativos sobre sua existência, muda o status de sujeito escravizado para individuo livre. Mas que não garantiu a ele a possibilidade de mobilidade social, nesta sociedade. Caso fosse representada por escalas é possível afirmar que esses seriam o nível mais baixo dela, pelo simples fato de sustentar o nível dominante. As relações de poder na verdade não mudavam, eram ressignificadas. No entanto, os papéis já estavam definidos pelo fato desses níveis serem opostos. (VIANA 2009, p.27-28).

Inquestionavelmente o sujeito alforriado, tanto no continente europeu, quanto aqui nos trópicos não teria a seu favor amparo social, pois o seu estereótipo construído e a sua real situação após a "liberdade". Desse modo este não contribui, e não contribuiria mais para o aumento do capital de seus senhores. A solução pensada para a falta da mão de obra foi o fomento da imigração de povos de países europeus. Já os negros ganharam as marginais por não terem onde residir, as cadeias por serem vadios e pela falta de trabalho, e o estigma de preguiçosos por não terem "vontade" por não terem as mesmas condições e oportunidades. 
O racismo neste caso ou a crença do não existir ideologicamente paralisa, pois o primeiro mostra e dá contornos de um abismo social, no segundo caso se trata de não reconhecer os malefícios socioculturais engendrados por ele até os dias de hoje, mesmo havendo políticas públicas para facilitar o acesso e inserção do negro na sociedade o racismo existe ocultado pela democracia racial em vários setores da sociedade, como visto na pesquisa do IBGE/PNAD(2016), onde os negros aparecem em indicadores sociais em números inferiores aos de pele não negra, ainda mais quando se percebe o grau de instrução para a entrada no mundo do trabalho. Segundo ARROYO, essa perspectiva pode e deve ser encarada:

\footnotetext{
É preciso colocar, entretanto, como ponto de partida, que a luta pelo direito à educação nos obriga a superar a visão dos educandos, das famílias e de seus grupos sociais como vítimas passivas da segregação. Somos obrigados a reconhecer suas resistências e suas afirmações como sujeitos do direito à educação. Em nossa história, as presenças afirmativas dos trabalhadores, pobres, negros, camponeses, indígenas, quilombolas afirmando-se sujeitos de direitos pressionam por outros reconhecimentos positivos e por outra função das escolas e por outras identidades docentes. (ARROYO 2015, p.18).
}

Entende-se então que a educação por meio da escola seria a provedora de um acesso social viável, justo e provedor de oportunidades através dos documentos e instrumentos curriculares e pelas suas práxis, o Brasil foi o último país a abolir a escravatura e a garantir direitos a essas pessoas, o capital neste caso influi no acesso a uma boa educação e consequentemente a boas oportunidades de trabalho. Para tal, o currículo em toda sua extensão precisa ser visto e entendido como será visto no capitulo a seguir.

\section{O CURRÍ́CULO}

Depois de todo traçado histórico e social proposto nos textos anteriores, se faz necessário entender como a escola apesar de ser produtora e difusora de cultura, acaba que por meio de seus documentos oficiais e de suas práticas, fomentar ou rechaçar as problemáticas advindas das negações dos grupos segregados que conseguem permanecer nas instituições que promovem a educação. Tal entendimento será feito por meio de uma abordagem sobre o currículo e as suas variantes tais, como: o oficial, o real e o oculto.

Para conceituá-lo é preciso entender que o currículo é definido de acordo com o contexto e demandas sociais no tempo vivido pelo indivíduo. Segundo SILVA (2005, p.11) 
“(...) O currículo é uma ferramenta que superaria o conceito e atua na tentativa de dizer o que é, e como é, cria um caminho tangível entre o embasamento teórico e os acontecimentos cotidianos". Sendo assim os estudos sobre o currículo apresentam uma leitura histórica e social que permite se observar situações de poder através de sua análise.

SACRISTÁN (2013, p.16) coloca que pode-se também definir currículo como um guia itinerário a seguir pelo educando em toda a sua carreira durante o curso, que se confirmam nas práticas, na estruturação dos tópicos e no grau de relevância dos mesmos.

Segundo Mendonça (2018) a espinha dorsal do currículo nasce na Idade Média na qual não se separa a ideia teocentrista do conhecimento a ser adquiridos pelos indivíduos. Assim imperavam o Trivium e o Quadrivium. O primeiro implementa a retórica, a gramática, e a lógica. Já o segundo era considerado a arte das coisas, pois o ensino era focado na aritmética, na geometria e na astronomia. A derivação dessa sistematização desencadeou o renascimento da escolástica, não como da antiguidade clássica que se dissociava do teocentrismo, mas uma releitura filosófica que permitia a sua entrada nos conceitos do trivium e do quatriviun. Mendonça (2018) reafirma a condição de currículo, quando explicita a condição de quem o faz, depois de passar por ele:

Saber as artes do triviun torna o ser humano mais completo, capaz de executar suas competências. Fazendo o triviun, fica mais fácil entender as artes do quadriviun. Quem chegava até o final dos estudos, depois de passar pelas sete artes liberais, recebia o título de mestre e poderia seguir para as artes liberais superiores, que na idade média, se reduzia ao Direito Canônimo, a Teologia e a Medicina. As artes liberais, naquela época, era um doutorado. (MENDONÇA, 2018 p-5).

No Brasil o primeiro contato que se houve com um documento semelhante com o currículo foi com a estruturação feita pela Companhia de Jesus, criada por Dom Inácio de Loyola em 1540, a ordem contribuiu para a expansão territorial pretendida pela Coroa portuguesa, e seu projeto educacional logrou êxito sobre a temática principal, que era a dominação do território dos povos encontrados pela missão dada a eles, através da catequização e o ensino da leitura e escrita em português, tendo como base o Ratio Studiorum. Como avaliam Shigunov Neto e Maciel:

O Projeto Educacional Jesuítico não era apenas um projeto de catequização, mas sim um projeto bem mais amplo, um projeto de transformação social, pois tinha como função propor e implementar mudanças radicais na cultura indígena brasileira. Ou seja, era um projeto de transformação social, pois tinha como função propor e implementar alterações profundas na cultura indígena brasileira 
Pode-se supor que o Projeto Educacional Jesuíticos Jesuítas, apesar de estar subordinado ao Projeto Português para o Brasil, tinha determinada autonomia, e teve papel fundamental na medida em que contribuiu para que o Governo português atingisse seus objetivos no processo de colonização brasileiro, bem como se constituiu no alicerce da estrutura educacional da Colônia brasileira. (SHIGUNOV NETO E MACIEL, 2008. P-173)

Quando as ideias iluministas começam aflorar no continente europeu, em Portugal, o Marquês de Pombal decide expulsar os jesuítas do comandando da educação na colônia não tendo incentivos para criação de outra estrutura de ensino, que ficaram a cargo das províncias, mas, mesmo assim, conseguem surgir algumas por volta de 1830. Haveria de se pensar um novo arranjo estruturante para que ocorresse a educação. Nesse meio tempo foi criada a primeira escola de ensino básico nacional, que levou o nome do Imperador Pedro II por volta de 1855, e tinha um currículo específico para cada nível de escolaridade, era notório a em todos os níveis a preocupação com a leitura, escrita, religião, aritmética entre outros.

O panorama não muda muito com a República até 1940, por meio de leis orgânicas organizaram de certo modo a educação e o currículo até ocorrer a primeira Lei de Diretrizes e Bases de $n^{\circ}$ 4024/1961, que demorou 14 anos até ser promulgada, unia esforços dos estados e união para que se sistematizasse conteúdos e disciplinas. Anos depois veio a 5692/1971 modifica a LDB 4024/1961, pensada no governo militar e torna a educação voltada para o ensino profissionalizante.

Em todos os cenários a educação atende uma necessidade social e por muitas vezes não se contempla a cultura mais sim questões ligadas ao capital. E pouco mudou essa relação que o currículo exerce desde o período jesuítico até os dias atuais, no sentido que se refere a poder. Pois a sua sistematização engloba as demandas sociais e o tipo de domínio pretendido por forças invisíveis que atuam na sociedade e no cotidiano escolar. Como SACRISTÁN (2013, p.18) evidencia no trecho a seguir:

\footnotetext{
O currículo determina que conteúdos serão abordados e, ao estabelecer níveis e tipo de exigências para grau sucessivos ordena o tempo escolar, proporcionando os elementos daquilo que entenderemos como desenvolvimento escolar e daquilo em que consiste o progresso dos sujeitos durante a escolaridade. Ao associar conteúdos, graus e idades dos estudantes, o currículo também se torna um regulador das pessoas. SACRISTÁN (2013, p.18)
}

Mas o que é o currículo de fato? "Ele regulamenta e estrutura os conteúdos a serem disseminados no decorrer de um curso, e que tem em si um extenso legado cultural, social, 
resultado de anos de produção histórica". Sabe-se que ele não é somente uma grade de conceitos a serem disseminados, o cumprimento dos tópicos dos documentos normativos que regem a educação, ele é a escola de fato, é o responsável pela criação de diversas identidades. Tudo isso se deve a forma que está estruturado.

O currículo então deveria ser visto e entendido e mais do que isso, construído, conforme as muitas culturas que construíram as formas de como se pensa educação no Brasil. Tem-se então conteúdos colonizados, e que não dialogam com as minorias que constituem este Estado e assim pouco os representa. Ainda mais quando se trata da escolha ou na omissão das ferramentas didáticas que se materializam por meio de livros didáticos, livros paradidáticos e plataformas integradas de ensino, que selam qualquer tipo de abertura paraoutras culturas a não ser a do colonizador, resultando num contato efêmero com o legado histórico até aqui produzidos por esses grupos marginalizados não dando possibilidades ao longo dos anos de um levante reivindicatório real, apesar de se ter a lei 10.639/2003 que em 2008 foi alterada pela 11.645/2008 que regulamenta o ensino da cultura africana e da luta dos povos afrodescendentes em seu artigo 26-A da LDB.

\footnotetext{
Art. 26-A.Nos estabelecimentos de ensino fundamental e de ensino médio, públicos e privados, torna-se obrigatório o estudo da história e cultura afrobrasileira e indígena.

$\S 1^{\underline{0}} \mathrm{O}$ conteúdo programático a que se refere este artigo incluirá diversos aspectos da história e da cultura que caracterizam a formação da população brasileira, a partir desses dois grupos étnicos, tais como o estudo da história da África e dos africanos, a luta dos negros e dos povos indígenas no Brasil, a cultura negra e indígena brasileira e o negro e o índio na formação da sociedade nacional, resgatando as suas contribuições nas áreas social, econômica e política, pertinentes à história do Brasil.

$\S 2^{\underline{0}}$ Os conteúdos referentes à história e cultura afro-brasileira e dos povos indígenas brasileiros serão ministrados no âmbito de todo o currículo escolar, em especial nas áreas de educação artística e de literatura e história brasileiras. (NR). (BRASIL, 2008.)
}

Pois, apesar da promulgação da lei acima citada, a coloniedade herança do legado colonizador que se perpetua e fortalece as diferenças dentro do currículo escolar, nega a possibilidade de se conceber uma escola menos excludente e mais pautada no respeito às diferenças. Por entender que o currículo deve atender as demandas sociais vigentes, e por haver uma democracia racial, que minimaliza as questões raciais, não há necessidade de se debater tal tema, pois dentro desta lógica o racismo já seria assunto superado. Logo o currículo e a sua sistematização, é a possibilidade de mudança na questão social. 
Decerto quando se fala em currículo, primeiro se pensa em conteúdos que devem ser apresentados antes de se fechar o ciclo ou ano letivo, muitas vezes deixando de fora as discussões que levaram aqueles conteúdos a fazerem parte de tal normativa. Ele apresenta três esferas, que são a oficial, a real e a oculta:

O oficial, é a forma oficial do currículo, ele tem orientação legal e normativo, tais como os PCN's e a BNCC, dentre outros. Age no âmbito superior, pois estabelece o que entra como conteúdo, estabelece um conteúdo mínimo. Os temas relacionados a cultura afro-brasileira entra nos documentos normativos por força da lei 11.645/08, entretanto há de se dizer que este tema tem datas pré definidas nas efemérides da maioria das instituições

No currículo real, se encontra o cotidiano da instituição, as possíveis adaptações curriculares, as relações entre os atores sociais, os caminhos a serem percorridos, as práticas ali realizadas, é o cumprimento do currículo oficial.

O currículo oculto, deriva de tudo aquilo que não entram no oficial e, é ali que pode abrigar negações e afirmações, adição ou subtração e que podem se traduzir em poder. Este tipo de currículo, envolve o cotidiano escolar, relação dos atores sociais, diz relação as diversas culturas, religiões e credos exaltados ou rebaixados.

\section{O CONCEITO DE CURRÍCULO NOS ATUAIS DOCUMENTOS CURRICULARES}

As leis e os atos normativos que derivam delas, influenciam bastante na dinâmica do ensino pois agem numa esfera macro, e intervém fortemente no currículo escolar. Podendose dizer que através dos aparatos legais e normativos que se é possível fazer o arranjo curricular desejado para as escolas da sociedade brasileira. Além das diretrizes e bases da educação nacional definidos pela lei 9394/96, exercem função importante na organização curricular das escolas as Diretrizes Curriculares Nacionais (DCN's), emanadas do CNE, e muito recentemente a Base Nacional Comum Curricular se constitui como importante e obrigatório documento norteador das práticas pedagógicas nas escolas.

A resolução no 4/2010 CNE/CEB, de 13 de julho de 2010 que fixa a Diretriz Curricular Nacional da Educação Básica um documento que privilegia um currículo escolar voltado para a cidadania, para o desenvolvimento integral dos sujeitos, e isso é expresso no artigo $13^{\circ}$ :

Art. 13. O currículo, assumindo como referência os princípios educacionais garantidos à educação, assegurados no artigo $4^{\circ}$ desta Resolução, configura-se como o conjunto de valores e práticas que proporcionam a produção, a 
socialização de significados no espaço social e contribuem intensamente para a construção de identidades socioculturais dos educandos. (Brasil, 2010.).

Já na Resolução CNE/CEB no 7, de 14 de dezembro de 2010, que é referente ao Ensino Fundamental conceitua currículo da seguinte forma:

Art. $9^{\circ} \mathrm{O}$ currículo do Ensino Fundamental é entendido, nesta Resolução, como constituído pelas experiências escolares que se desdobram em torno do conhecimento, permeadas pelas relações sociais, buscando articular vivências e saberes dos alunos com os conhecimentos historicamente acumulados e contribuindo para construir as identidades dos estudantes. (Brasil, 2010.).

Na Resolução N5, de 17 de Dezembro de 2009, que diz respeito à Educação Infantil, define em seu Art. $3^{\circ}$ que:

O currículo da Educação Infantil é concebido como um conjunto de práticas que buscam articular as experiências e os saberes das crianças com os conhecimentos que fazem parte do patrimônio cultural, artístico, ambiental, científico e tecnológico, de modo a promover o desenvolvimento integral de crianças de 0 a 5 anos de idade. (Brasil, 2009.).

No ano de 2017 após amplo debate foi publicada a Base Nacional Comum Curricular que se constitui como referência nacional para que os todos os entes federados possam organizar o currículo escolar de forma a garantir que haja de fato a democratização do acesso a um padrão mínimo de conhecimento a todos os alunos estando eles matriculados em escolas públicas ou privadas. De acordo com o documento: “...para além da garantia de acesso e permanência na escola, é necessário que sistemas, redes e escolas garantam um patamar comum de aprendizagens a todos os estudantes, tarefa para a qual a BNCC é instrumento fundamental. (BNCC p.10).

Diante do exposto podemos perceber que o conceito de currículo embora definido de formas diferenciadas nos documentos apresentados, todas as definiçõos trazem em comum o princípio de que o currículo está em constante construção no cotidiano das escolas e que por meio dele deve ser garantido a todas as pessoas o acesso a conhecimentos necessários para que se desenvolvam num contexto de respeito às diversas pessoas que estão na escola e logicamente às suas culturas e etnias de forma a privilegiar a equidade. Entretanto, parece ser bastante difícil vivenciar isto realmente em espaços escolares que por meio do currículo oculto ainda servem para reforçar o racismo mesmo que em seu currículo oficial o mito da democracia racial esteja bem presente. 


\section{O CURRÍCULO A CONSTRUIR}

O currículo a construir, precisa superar os arranjos curriculares já apresentados. Entende-se que a escola é o lócus propício para que ocorra uma resposta as problemáticas presentes na sociedade. Por muito tempo se acreditou que uma sociedade, que era fruto de uma colonização híbrida e multicultural abria-se um leque de possibilidades aos seus integrantes de uma forma a contemplar a igualdade. É pela disseminação de ideias como essas que fazem o mito da democracia racial ser aceito por grande parte da população brasileira, entre eles os de descendência africana também. A crença numa suposta igualdade, traz uma visão romantizada e se recusa a discutir as problemáticas das diferenças, que é posta à prova e se confronta com as diversas formas de racismo. Nada diferente dos panoramas sociais anteriores.

Crendo nessa falácia do não existir o racismo, e da convivência pacífica blindada pelo mito, a instituição escola não tem aberto as discussões como se deveria, trata do tema de forma esporádica e superficial tanto na educação infantil, quanto nos anos iniciais do ensino fundamental. Neste sentido a lei 11.645/08 é clara em seu Art.26-A inciso§ $2^{\circ}$ que definindo que "O legado dos povos afrodescendentes e indígenas, serão ministrados de forma contínua..." Ganhando peso de lei, para se fazer o que era lógico, no entanto estes conteúdos deveriam ser lecionados não por obrigatoriedade, mas por justiça social. Esse é o tipo de educação proposta por Lopes “... Na qual reconheça que afrodescendentes e indígenas, segregados sociais, tenham as suas problemáticas históricas discutidas no currículo, aponto de serem capazes de reconhecê-las, criando sujeitos que possam dar como resposta, uma sociedade mais justa.”(LOPES, 2005, p.185-186).

Os currículos oficiais "teoricamente" dentro de seu currículo mínimo, tem demarcado a importância de se conhecer a historicidade dos atores envolvidos no processo de ensino aprendizagem, pois é fruto de uma sociedade multicultural, logo deve contemplar também a cultura africana. Entretanto, isso só pode ocorrer através das práxis elaboradas pelos profissionais de educação na valorização dessas minorias junto aos educandos, trabalhando um conjunto de especificidades que mostre a representatividade e a importância dos negros na construção do Estado brasileiro, ajudaria na mudança de olhar sobre o mito racial em relação ao racismo de fato. Aí se deve a importância da escola com todo o seu aparato humano e didático, como Lopes relata: 


\begin{abstract}
A educação deve ajudar professor e alunos a compreenderem que a diferença entre pessoas, povos e nações é saudável e enriquecedora; que é preciso valorizálas para garantir a democracia que, entre outros, significa respeito pelas pessoas e nações tais como são, com suas características próprias e individualizadas; que buscar soluções e fazê-las vigorar é uma questão de direitos humanos e cidadania. Aprendendo a se ver, a ver o seu entorno (família, amigos, comunidade imediata) de modo objetivo e crítico, a comparar todos esses elementos com os de outros tempos e lugares, a criança desenvolve comportamentos adequados para viver numa sociedade democrática. (LOPES, 2005, p-188).
\end{abstract}

Logicamente as práticas e os instrumentos pedagógicos decorrentes de um currículo real construído para a equidade, pensará nas culturas negadas pelo próprio sistema como um todo. O caminho a ser construído deve ter práticas variadas, tais como teatro, feiras, rodas de leituras, contação de histórias. Práticas que comuns ao meio escolar, mesmo que haja instrumentos didáticos na instituição, o trabalho não se faz sozinho, é preciso postura dos profissionais envolvidos no processo, como salienta Mantoan:

Sem estabelecer uma referência, sem buscar o consenso, mas investindo nas diferenças e na riqueza de um ambiente que confronta significados, desejos e experiências, o professor deve garantir a liberdade e a diversidade das opiniões dos alunos. O professor, da mesma forma, não procurará eliminar as diferenças em favor de uma suposta igualdade do alunado, que é tão almejada pelos que apregoam a (falsa) homogeneidade das salas de aula. Antes, estará atento à singularidade das vozes que compõem a turma, promovendo o diálogo entre elas, contrapondo-as, complementando-as. (MONTOAN, 2003. p.41-42)

A construção deste currículo será feito pela luta, que se caracterizam por diferentes vozes em busca de representatividade, que venha contestar o modelo presente nas instituições escolares, como mostram MOREIRA E CANDAU:

Questionar os lugares comuns, as leituras hegemônicas da nossa cultura e de suas características, assim como das relações entre os diferentes grupos sociais e étnicos, constitui outro aspecto que carece discutir e aprofundar. $\mathrm{Na}$ medida das possibilidades, outro ponto a ser trabalhado é a interação com diferentes grupos culturais e étnicos. A intenção é propiciar uma interação reflexiva, que incorpore uma sensibilidade antropológica e estimule a entrada no mundo do "outro". (MOREIRA E CANDAU, 2003. p.167).

Logo é preciso seguir para uma nova construção curricular, feita através de seus personagens, conscientes de seu papel como cidadãos, mas que para isso tenham subsídios para reconhecer as mazelas impostas pela não aceitação das diferenças, que na cotidianidade da escola e na sociedade repercute como preconceito, racismo e infelizmente desencadeia o mito racial. 


\section{O CURRÍCULO NO LÓCUS ESCOLAR}

Para se entender como e por onde começar a construção de um novo currículo que privilegie as questões raciais deve-se em primeiro voltar olhar para o lócus escolar e observar o quanto os profissionais estão imersos no tema, quais qualificações obtiveram, se os materiais didáticos e para didáticos se apresentam de forma a corroborar para que ocorra a promoção do diálogo.

Neste sentido foi realizada uma entrevista em instituições pública e privada de ensino da cidade de São Gonçalo/RJ. Participaram7 pessoas de cada uma delas. A escola da rede pública só atende o ensino fundamental I, e conta com um programa de qualificação continuada para professores, materiais didáticos e paradidáticos de programas de cunho federal. Já a escolada rede privada os entrevistados atuam na educação infantil e ensino fundamental, os cursos de qualificação ficam por conta de grupos editoriais parceiros, ou dos próprios profissionais em sua maioria das vezes, em relação aos materiais didáticos, obedecem ao planejamento curricular da instituição.

Todos os participantes assinaram o Termo de Consentimento Livre e Esclarecido respeitando a ética em pesquisa com pessoas, onde os entrevistados eram informados sobre as informações prestadas. Além das entrevistas também foram feitas consultas aos materiais didáticos do acervo das duas instituições, e os projetos realizados por elas. $\mathrm{O}$ conteúdo das entrevistas foi analisado na perspectiva da análise de conteúdo de Bardin (2011).

O resultado das entrevistas evidencia o pouco conhecimento do professorado em relação ao acervo relativo à temática racial disponível, sendo possível notar por exemplo, os livros paradidáticos citados como indicação, na pesquisa, os títulos pouco divergem. Sendo o mais conhecido o título Menina Bonita do Laço de Fita.

$\mathrm{Na}$ primeira questão, os profissionais da escola pública mesmo tendo um acervo enviado pelo PNAIC com diversos livros sobre a temática perguntada, apenas dois de sete entrevistados conheciam algum livro. Já na escola privada a situação se inverte, apesar de não ter um grande acervo com o tema perguntado, cinco dos sete entrevistados conheciam algum dos livros citados.

Quando se pergunta sobre qual o título mais importante que fora trabalhado em sala de aula que aludiam questões étnicas, os números de discursos das escolas pública e privada 
se igualam, quatro de sete entrevistados, usaram uma mesma literatura (Menina Bonita do Laço de Fita).

Todos os entrevistados foram unânimes em dizer que os livros didáticos e paradidáticos indicados ou recebidos são relevantes para o trabalho docente. Perguntadas sobre a existência de práticas da cotidianidade voltadas para o temática em estudo, foi afirmado pelas entrevistadas que nas duas instituições não foram realizadas dentro da cotidianidade da escola, feira, projeto e nem exposições dentro da temática racial.

As respostas na questão de número cinco se igualam, quando se pergunta se há um conteúdo que se julgue como necessário, pois em nenhuma aparecem temas ligados ao legado histórico produzido pelos povos africanos.

Na questão de número seis onde perguntamos sobre quantas festas escolares dentro do tema racial aconteceram nas instituições este ano letivo, na instituição privada não ocorreu nenhuma mobilização para tal, já na instituição pública ocorreu a culminância de um projeto para que se fosse possível a reposição de carga horária, sendo realizado em sábado letivo e a temática trabalhada foi o continente Africano, e teve adesão de todos os professores entrevistados, porém ao se referir a esta atividade na pesquisa somente quatro disseram ter ciência da mesma.

E para finalizar as questões de número sete e oito, que queriam apurar qual eram as qualificações que os profissionais têm ou que gostaria de ter em formações, nenhum dos entrevistados citou ou indicou cursos de qualificação sobre o tema em pesquisa.

\section{APRESENTANDO A FESTA DA CULTURA IMIGRANTE:}

Neste momento será apresentada experiência de cumprimento curricular, a Festa da cultura imigrante, realizada no Colégio Municipal localizado no município de São GonçaloRJ, onde a atividade proposta fez parte do sábado letivo da escola, e foi aberto a comunidade. Os graduandos do curso de pedagogia do Curso Superior Anísio TeixeiraISAT que fazem parte do Projeto Residência Pedagógica da CAPES, trabalhou o tema África em um projeto, a pedido da preceptora Esmeralda Cristina, cada grupo de residentes pesquisou e construiu o conhecimento junto aos educandos da instituição. Os trabalhos ficaram divididos entre os grupos de espaço maker, brinquedoteca e contação de história. Lá foi abordada, a situação de como os negros chegaram ao Brasil, as músicas e seus instrumentos, as danças, os contos, os tipos de brinquedos, brincadeiras e a culinária. 




Fig.1: Construção de navios negreiros.

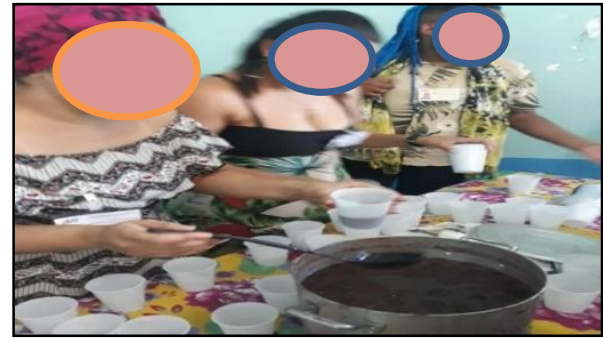

Fig.2: Culinária Africana.

A aprendizagem aconteceu de forma a ser significativa tanto para os alunos e professores, quanto para os residentes como propõe Moreira e Candau (2003).
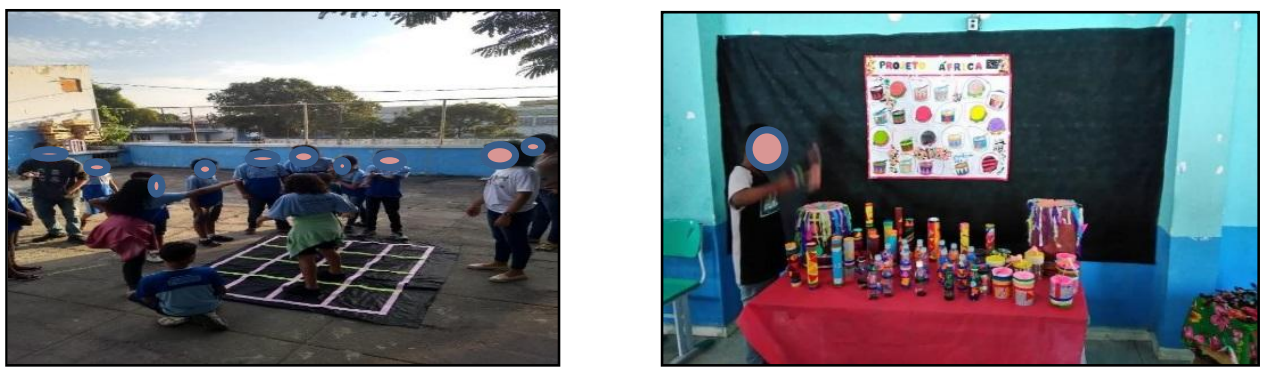

Fig.3: Amarelinha africana

Fig.5: Instrumentos da cultura africana.

Nesta perspectiva, a experiência obtida, fomentou a discussão sobre a temática racial, quando os professores regentes precisaram atuar junto com os graduandos de pedagogia, definindo pesquisas e práticas relevantes as turmas, quando mostraram aos educandos a importância dos negros na construção do Estado brasileiro, quando articulou corpo docente, discente e comunidade escolar. Práticas como esta que dão o tom da luta diária por um currículo que privilegie e reconheça a luta dos povos afrodescendentes e que não negue o racismo, e que assuma o compromisso de se expor às mazelas criadas por esta negação.

\section{CONSIDERAÇÕES FINAIS}

O mito da democracia racial se faz presente no cotidiano do povo brasileiro, negar o racismo virou uma ideologia ilusória, que não nos deixa perceber o erro de não se reconhecê-lo. Quando não se reconhece tais questões, o caminho é reverso e controverso, pois os produtos raciais que estão inseridos na sociedade ganham força e contornos.

É por meio da escola que se pode contribuir para mudar o panorama que ainda incide na sociedade, através do seu currículo e pelos seus atores sociais, fomentando debates, 
atuando e proporcionando meios de qualificação docente para o cumprimento da lei 11.645/08 de forma literal e contextualizada, fazendo com que os afrodescendentes se reconheça e perceba a sua importância no legado histórico de seus antepassados na

construção deste país. É preciso que reconheçam o seu protagonismo mesmo que e que sua história possa virar o currículo real da escola.

Por isso é fundamental a composição de um currículo que tende ser liberto do colonialismo, e que possa passar a ter uma visão multicultural, contemplando as minorias, refletindo isso para além da escola, para que cenas de racismos e de adoração ao mito racial venham cair por terra; e se possa assumir um compromisso com a mudança onde os indicadores sociais do IBGE, por exemplo, venha de fato dar motivos para se dizer que houve melhora na vida das pessoas de pele não branca. Logo o trabalho é árduo, as qualificações devem ser encaradas como imprescindíveis, mas um análise das praticas cotidianas com vista á superação das praticas racistas presentes no currículo oculta se tornam também necessárias.

\section{REFERÊNCIAS BIBLIOGRÁFICAS}

ARROYO. Miguel G.O Direito à Educação a Nova Segregação Racial-Tempos

Insatisfatórios? Disponível em>http://www.egov.ufsc.br. Acessado em 24 de fevereiro de 2019. (2015, p.18).

BARDIN, Laurence (2011). Análise de Conteúdo. Tradução: Luis Antero Reto, Augusto Pinheiro. São Paulo: Edições, 70 LDA/Almedina Brasil.

BENTO, Maria Aparecida Silva. Cidadania em Preto e Branco: Discutindo as Relações

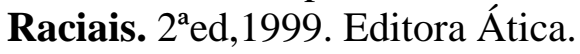

BRASIL. Base Nacional Comum curricular (2018). Disponível em>http://basenacionalcomum.mec.gov.br/. Acessado em 30 de julho de 2019. (2018, p$10)$.

BRASIL. Constituição Federal (1988). Disponível em>http://www.planalto.gov.br/ccivil. Acessado em 25 de maio de 2019.

BRASIL. Ministério da Educação Conselho Nacional de Educação Câmara de Educação Básica. RESOLUÇÃO No 5, DE 17 DE DEZEMBRO DE 2009 (*) Fixa as Diretrizes Curriculares Nacionais para a Educação Infantil. Disponível em>http://portal.mec.gov.br/. Acessado em 27 de julho de 2019. 
BRASIL. Ministério da Educação Conselho Nacional de Educação Câmara de Educação Básica. RESOLUÇÃO No 4, DE 13 DE JULHO DE 2010 (*). Disponível em> http://portal.mec.gov.br/dmdocuments/rceb004_10.pdf. Acessado em 27 de julho de 2019.

BRASIL. Ministério da Educação Conselho Nacional de Educação Câmara de Educação Básica. RESOLUÇÃO No 7, DE 14 DE DEZEMBRO DE 2010 (*). Disponível em > http://portal.mec.gov.br/dmdocuments/rceb007_10.pdf. Acessado em 11 de agosto de 2019.

CALOTI, Vinícius de Aguiar; AMORIM, Cleyde Rodrigues. Considerações sobre o racismo no Brasil, a partir das representações acerca do negro, no imaginário das Escolas Públicas, na Grande Vitória-ES. Revista Simbiótica v. 2, n. 1 (2015) Issn 2316-1620

FREYRE, Gilberto. Casa-Grande e Senzala. Editora Global, 49ª ed. São Paulo. 2004. Capítulo 1.

GONÇALVES, Luciane Ribeiro Dias. Educação das Relações Étnico-Raciais: O Desafio da Formação Docente. Disponível no site da ANPED - Associação Nacional de PósGraduação e Pesquisa em Educação - http://www.anped.org.br. Acessado em 9 de abril de 2018.

GUIMARÃES, Antonio Sérgio Alfredo. Democracia Racial: o ideal, o pacto e o mito. Disponível em >https://www.anpocs.com. Acessado em 26 de agosto de 2018.

LOPES, V.N.Racismo, preconceito e discriminação. In: MUNANGA, K (Org.). Superando o racismo na escola. Brasília: Ministério da Educação, Secretaria de Educação Continuada, Alfabetização e Diversidade, 2005.p.185-188.

MENDONÇA, Welton Pereira de. A Eficácia do Trivium e do Quadrivium Como Métodos de Ensino Utilizados na Idade Média. Disponível em >http://www.computacao.unitri.edu.br/erac/index.php/e-rac/article/view/1209. Acessado em 21 de julho de 2019.

MONTOAN. Maria Eglér. Inclusão escolar: O que é? Por quê? Como fazer? (Coleção cotidiano escolar) Editora Moderna, $1^{a}$ ed. São Paulo, 2003. (p.41-42).

MOREIRA, Antonio Flavio Barbosa; CANDAU, Vera Maria. Educação escolar e cultura(s): construindo caminhos. Disponível em > http://www.scielo.br/pdf/rbedu/n23/n23a11. Acessado em 5 de agosto de 2019.

REIS, Fábio Wanderley. Mercado e Utopia. Rio de Janeiro: Centro Edelstein de Pesquisas Sociais, 2009. Disponível em < http://books.scielo.org. Acessado em 23 de abril de 2018.

Retrato das Desigualdades de Gênero e Raça - 1995 a 2015. Disponível em http://www.ipea.gov.br. Acessado em 24 de novembro de 2018.

Retratos Revista do IBGE. Somos Todos Iguais? O que dizem as Estatísticas. No 11 maio 2018. Disponível em >https://agenciadenoticias.ibge.gov.br/agencia-noticias. Acessado em 25 de novembro de 2018.

SACRISTÁN, José Gimeno. Saberes e incertezas sobre o currículo. Porto Alegre: Penso, 2013.Capítulo 1 
SANTOS, Cleito Pereira dos e VIANA, Nildo (orgs.). Capitalismo e Questão Racial. Rio de Janeiro: Corifeu, 2009.

SANTOS, Joel Rufino dos. O que é o Racismo. Coleção primeiros passos, vol. 8.ed Abril Cultural e Brasiliense, 1984.

SHIGUNOV NETO, Alexandre; MACIEL, Lizete Shizue Bomura. O ensino jesuítico no período colonial brasileiro: algumas discussões. Disponível

em>http://www.scielo.br/pdf/er/n31/n31a11.pdf. Acessado em 21de julho de 2019.

SILVA, José Bezerra da; BERTOLDO, Maria Edna. O racismo como subproduto da sociedade de classes. Disponível

em>http://www.periodicos.uem.br/ojs/index.php/EspacoAcademico/article/view. Acessado em 17 de fevereiro de 2019

SILVA, Tomaz Tadeu da. Documentos de Identidade: uma introdução às teorias do currículo. Belo Horizonte: Autêntica, 2005. ( p.22). 